\title{
HOW REPRODUCIBLE ARE THE EFFECTS OF A MICROPROCESSOR FOOT?
}

\author{
Michael McGrath ${ }^{* 1}$, Nadine Stech ${ }^{1}$, Piotr Laszczak ${ }^{1}$, Alan Kercher ${ }^{2}$, Saeed Zahedi $^{1}$, David Moser ${ }^{1}$ \\ ${ }^{1}$ Endolite Technology Centre, Basingstoke, UK \\ ${ }^{2}$ Endolite North America, Miamisburg, OH, USA \\ "Email: mike.mcgrath@blatchford.co.uk
}

\section{INTRODUCTION}

Using microprocessor-control to dynamically adapt hydraulic ankles, by changing the resistances to dorsiflexion and plantarflexion (DF/PF) movements, has been shown to have beneficial biomechanical effects during slope descent ${ }^{1}$. Another, more recent case study also showed that the level walking biomechanical effects of microprocessor-feet (MPF) persist, and the same trends can be observed in repeated gait analysis sessions, over a year apart ${ }^{2}$. This work looks to expand on both of these concepts, analysing repeated gait analysis sessions to see if the biomechanical changes of MPF during slope descent are reproducible over time.

\section{METHODS}

A mixed cohort of trans-tibial and trans-femoral, K3 amputees participated in this study. Each was fitted with a microprocessor-controlled hydraulic ankle-foot (Elan, Endolite), which dynamically varies the resistances to dorsi-/plantarflexion (DF/PF) depending on the gradient of the walking surface. Two prosthetic conditions were tested, in a randomised order. These included one with the dynamic resistance variation active (MPF-on) and one without (MPF-off), so that the device behaved like a regular hydraulic ankle, with constant resistance to $\mathrm{DF} / \mathrm{PF}$. Each participant was asked to descend a $5^{\circ}$ slope at their comfortable walking speed. A $5^{\circ}$ slope was selected as this aligns with the ADA regulations regarding disability access ramps - a common real-life environmental barrier. Kinematic and kinetic measurements were recorded using a gait analysis system and a force plate embedded in the sloped surface. Each participant was recorded for two different data collection sessions, at least a month apart.

\section{RESULTS}

The findings showed a number of gait parameter changes that were reproduced in the different testing sessions. While quantitative changes were different, even within participants, the observable changes were in the same direction each time. The most consistent changes occurred at the prosthetic 'ankle'. The transition from DF

moment to PF moment at the prosthetic 'ankle' consistently occurred earlier in the gait cycle with the MPF-on. This implied that there was less resistance to PF movement, so a stable 'foot flat' position was achieved sooner and so did the change from 'heel rocker' to 'ankle rocker'. The earlier transition meant that there was an increased resistance to DF movement, implying a braking effect to control momentum build up. This effect was also seen as increased negative 'ankle' work done. These same trends were observed for both trans-tibial and trans-femoral amputees, showing reproducibility regardless of amputation level.
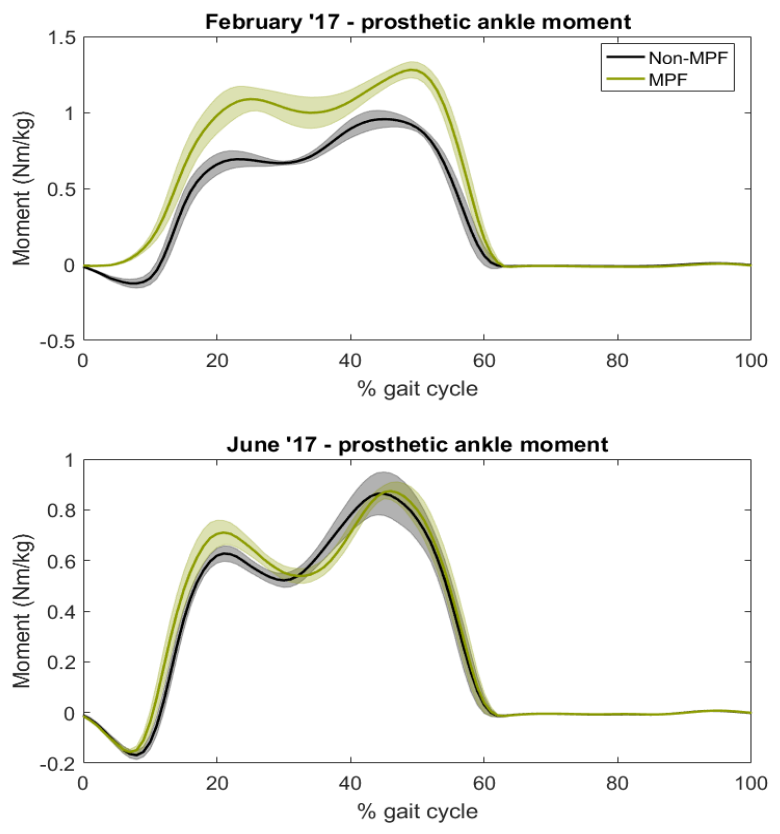

Figure 1: The prosthetic 'ankle' moment plots for a trans-tibial amputee with MPF-off (black) and MPF-on (green), for test sessions four months apart.

\section{CONCLUSION}

It is not simply the function of a prosthetic device that is important but also the consistency of that function. A 
consistent performance will improve user confidence in a prosthetic device and highlights the potential to influence long term health problems, such as osteoarthritis and back pain, both of which are common among the amputee population ${ }^{3}$.

\section{SIGNIFICANCE}

Showing reproducibility of the effects of MPFs indicates that there will be an influence on the long term biomechanics of the user.

\section{REFERENCES}

1.Struchkov et al. Biomechanics of ramp descent in unilateral trans-tibial amputees: Comparison of a microprocessor controlled foot with conventional ankle-foot mechanisms. Clin Biomech. 2016;32:164-170. DOI: $\underline{10.1016 / \text { j.clinbiomech.2015.11.015 }}$

2.De Asha et al. Which Prosthetic Foot to Prescribe?: Biomechanical Differences Found during a Single-Session Comparison of Different Foot Types Hold True 1 Year Later. J Prosthet Orthot. 2017;29(1):39-43. DOI:10.1097/JPO.0000000000000119

3.Gailey. Review of secondary physical conditions associated with lower-limb amputation and long-term prosthesis use. $J$ Rehabil Res Dev. 2008;45(1):15-29. DOI: 10.1682/JRRD.2006.11.0147

\section{DISCLOSURE}

The Authors are employees of Endolite North America or Blatchford (the parent company of Endolite North America); the manufacturer of the ankle-foot devices used in this study. 